\title{
ENTRE EXPECTATIVAS E EXPERIÊNCIAS: \\ A GÊNESE DO LABORATÓRIO DE ESTUDOS E PESQUISAS EM DIDÁTICA DA HISTÓRIA (LEPEDIH) DA UNESP/ASSIS
}

\begin{abstract}
BETWEEN EXPECTATIONS AND EXPERIENCE: THE GENESIS OF LABORATORY OF STUDIES E RESEARCHES IN HISTORY TEACHING (LEPEDIH) OF UNESP/ASSIS
\end{abstract}

Ronaldo Cardoso Alves ${ }^{1}$

\begin{abstract}
RESUMO: O artigo tem como objetivo apresentar alguns elementos que deram origem ao Laboratório de Estudos e Pesquisas em Didática da História da UNESP/Assis, a fim de mostrar diferentes possibilidades de pesquisa em Ensino de História, por meio do repertório epistemológico da teoria da consciência histórica, proveniente da Didática da História, tendo em vista a discussão a respeito da função pública da História.
\end{abstract}

Palavras-Chave: Didática da História. Consciência Histórica. Ensino de História. Aprendizagem Histórica. Educação Histórica.

ABSTRACT: The article aims to present some elements that gave rise to the Laboratory of Studies and Research on Didactic of History UNESP/Assis in order to demonstrate different possibilities of research in Teaching History, through the epistemological repertoire of the theory of historical consciousness, coming from the Didactic of History, with a view to discussion on public function of history.

Keywords: Didactic of History. Historical consciousness. Teaching of history. Historical learning. History Education.

\footnotetext{
${ }^{1}$ Professor do Departamento de Educação da Universidade Estadual Paulista (UNESP), Campus Assis,
} 
Não te deixes destruir... Ajuntando novas pedras e construindo novos poemas. Recria tua vida, sempre, sempre. Remove pedras, planta roseiras e faz doces.

Recomeça.

Faz de tua vida mesquinha um poema. E viverás no coração dos jovens e na memória das gerações que hão de vir. Esta fonte é para uso de todos os sedentos. Toma a tua parte. Vem a estas páginas e não entraves seu uso aos que têm sede. "Aninha e suas pedras" (Outubro, 1981).

\section{I}

A epígrafe deste artigo, escrita por Ana Lins do Guimarães Peixoto Brêtas, mais conhecida por seu pseudônimo, Cora Coralina, apresenta alguém que, mesmo na altura de seus 92 anos, observa a vida em suas experiências temporais, de forma densa, viva e plenamente humana. A poetisa, que viveu quase 96 anos, como se estivesse na janela de sua simples casa na linda cidade de Goiás, põe-se a observar o correr da vida - filhos, netos, bisnetos, amigos, conhecidos, até mesmo desconhecidos - e reconhece na simplicidade do fazer doces, nas dificuldades dos obstáculos da existência histórica, na alegria perene da criação da vida expressa no simples ato de plantar e, sobretudo, no abdicar da tentadora existência narcísica, a possibilidade de permitir-se que da própria vida suscite a força existente no ato da "poiesis", palavra grega que pode ser traduzida como "feitura", ou seja, da ousada ação reflexiva que permite viver diferentemente, criar experiências, abrir horizontes, novas expectativas que são e serão para aqueles que vivem e para os que hão de vir.

Ao constituir sentido à sua própria ação histórica, a narradora vê nas dificuldades das experiências históricas a potência para construir novas experiências que apontam para uma rediviva esperança da expectativa a ser vivenciada pelas futuras gerações. Do alto de sua experiência resiste a conformar-se ao existente, questiona a reprodução de ideias, a prescrição de modelos que visem a perpetuação de experiências e expectativas padronizadas às novas gerações. Propõe o novo. Rompe com as estruturas existentes, idealizando novas experiências com o objetivo de abrir-se a novas possibilidades,

e coordenador do LEPEDIH - Laboratório de Estudos e Pesquisas em Didática da História. 
um horizonte de expectativas às gerações vindouras.

O dilema acima apresentado não ocorre somente com a narradora da canção, mas se apresenta na experiência histórica de todos os seres humanos cotidianamente. Remover, recriar, ajuntar, construir, plantar, fazer, são verbos que propõem a constituição de novos sentidos à vida, em outras palavras, ações que promovem a reflexão a respeito do antigo, a criticidade, a proposição de novas ideias. Desde as simples até as mais complexas experiências, individuais e coletivas, a racionalidade histórica atua, em maior ou menor grau, com a finalidade de constituir sentido à vida, ou, em outras e curtas palavras, para construir consciência histórica.

Para "Aninha" a História não se trata de uma coleção de fatos no tempo, mas se constitui em processo. Processo que convida à problematização, à ação, à constante (re)criação, independentemente da duração da vivência histórica, pois aqueles que tomam sua parte e resolvem agir, deixam como legado experiências que não cabem dentro de sua própria existência histórica, mas que podem ensejar a abertura de horizontes de expectativas que poderão transformar-se em experiências históricas das novas gerações.

A leitura de tais palavras, no início de um artigo voltado para um dossiê que trata da formação de professores de História no século XXI, pode soar um tanto estranha. Normalmente, num espaço como este se pensaria no estudo de diferentes metodologias, novas técnicas, materiais, currículos, entre tantas coisas que são, obviamente, temáticas importantíssimas da formação docente e, necessariamente, demandas de importante reflexão.

Entretanto, este artigo tem como objetivo apresentar experiências que deram origem ao Laboratório de Estudos e Pesquisas em Didática da História (LEPEDIH) da Universidade Estadual Paulista (UNESP), Campus Assis, a fim de discutir diferentes possibilidades de pesquisa em Ensino de História, por meio do repertório epistemológico da teoria da consciência histórica (oriunda da Didática da História alemã), com vistas à discussão em torno da função pública da História. Obviamente que não há ineditismo em experiências deste tipo. Muito longe disso. São experiências que gerações de pesquisadores já passaram quando ousaram discutir cientificamente o ensino de História em seus espaços acadêmicos, ou mesmo quando se inquietaram em dizer e mostrar que a produção histórica é fundamental, importantíssima para a vida das pessoas e, exatamente por isso, 
deve estar em profunda e permanente conexão com espaços escolares - lugar ímpar no qual professores-historiadores podem contribuir para que o conhecimento histórico efetivamente ecoe no pensar de crianças, adolescentes e jovens - assim como em espaços extraescolares, de forma que se possa pensar nas diferentes maneiras pelas quais o conhecimento histórico tem se encontrado com o público - espaços museológicos, meios de comunicação, entre outros.

Nesses tempos sombrios em que o Brasil passa por um recrudescimento conservador, numa crise política, ética e econômica, muitos professores de História, na universidade e na escola básica, perguntam-se a respeito do sentido da ocorrência, em manifestações e em redes (anti)sociais, de átimos de defenestração a educadores como Paulo Freire, acompanhados de discursos que, veja só, solicitam intervenção militar para organização do país! Ironia observar, caro leitor que, para "preservar" a democracia, ensejam o reavivar da ditadura. Para expectar um "pseudo" horizonte democrático, requerem a experiência ditatorial, a mesma que suprimiu o horizonte de expectativa da democracia de toda uma geração de brasileiros.

Não há uma única resposta para tal problema. As dificuldades são muitas, podendo-se pensar em discutir desde questões estruturais referentes aos equívocos das políticas públicas brasileiras voltadas à educação, passando pelo distanciamento da universidade em relação à escola pública de ensino básico até, especificamente, a mentalidade bacharelesca presente nos cursos de licenciatura que visa desconstruir a expectativa de muitos estudantes em tornarem-se professores. Em curtas palavras, a pesquisa é valorizada em detrimento dos outros pilares da formação universitária brasileira: o ensino e a extensão. Claro que este último item se refere maciçamente às instituições públicas, pois são estas que, efetivamente, fazem pesquisas no país, dado o alto custo de investimento.

Percebe-se, neste momento inicial do presente texto, que a formação de pesquisadores e professores de História demanda, dos profissionais da área do Ensino de História, o questionamento da mentalidade perene de desvalorização da relação entre História e Educação, a qual grassa, salvo raríssimas exceções, nos cursos de licenciatura espalhados pelo país. 
A mudança de mentalidade coletiva passa, obviamente, pela mudança de percepção a respeito de si (self) no encontro com a História, fator que pode ser observado na linda poesia citada na epígrafe. Entretanto, tal ação não é nova. Reinhart Koselleck, historiador alemão, percebeu na crítica feita pelos iluministas à crise estrutural do Antigo Regime - de liberais a progressistas; de reformistas a revolucionários - a origem da consciência histórica moderna. Para ele, a Filosofia das Luzes transformou a História em processo ao propagar a ideia de que cabia aos seres humanos, desprezados pelo sistema vigente, o protagonismo de um novo momento, ou seja, "[...] Não se pode mais esperar conselho a partir do passado, mas sim apenas de um futuro que está por se constituir" (KOSELLECK, 2006, p. 58). As experiências passadas já nada significavam. Era preciso constituir novo sentido à vida, pois "[...] não há expectativa sem experiência, não há experiência sem expectativa"² (KOSELLECK, 2006, p. 307).

Nessa perspectiva, futuro e passado se encontraram à medida que a demanda do presente histórico era "criar" o novo, "(re)começar", "removendo as pedras" impostas pelo passado do Antigo Regime, construindo o novo por meio do entremear do "plantar roseiras (com seus espinhos)" e "fazer doces", presentes na racionalidade iluminista que propunha novas possibilidades de ser, fazer e viver História. Assim, consciência histórica, nessa perspectiva é a

[...] atividade composta por operações mentais que se desenvolvem de acordo com a importância e o sentido que terão para os próprios indivíduos em sua relação consigo mesmos e com o mundo que os cerca. [...] Trata-se do trabalho intelectual que tem como objetivo relacionar as experiências vivenciadas pelos seres humanos ao longo da História às expectativas geradas nesse

\footnotetext{
2 Para Koselleck "[...] experiência e expectativa são duas categorias adequadas também para nos ocuparmos com o tempo histórico, pois elas entrelaçam passado e futuro. São adequadas também para se tentar descobrir o tempo histórico, pois, enriquecidas em seu conteúdo, elas dirigem as ações concretas no movimento social e político" (2006, p. 308). Experiência é "[...] o passado atual, aquele no qual acontecimentos foram incorporados e podem ser lembrados. [...] na experiência de cada um, transmitida por gerações e instituições, sempre está contida e é conservada uma experiência alheia. Nesse sentido, também a história é desde sempre concebida como conhecimento de experiências alheias" (2006, p. 309-310). A Expectativa, por sua vez "[...] também ela é ao mesmo tempo ligada à pessoa e ao interpessoal, também a expectativa se realiza no hoje, é futuro-presente, voltado para o ainda-não, para o não-experimentado, para o que apenas pode ser previsto. Esperança e medo, desejo e vontade, a inquietude, mas também a análise racional, a visão receptiva ou a curiosidade fazem parte da expectativa e a constituem" (2006, p. 310).
} 
mesmo processo. Nesse sentido, ter consciência histórica é apropriar-se das operações mentais do pensamento histórico com o objetivo de refletir sobre as experiências vivenciadas por si e/ ou pelo(s) outro(s) no decurso do tempo a fim de satisfazer expectativas concebidas no presente ou mesmo criar novas expectativas a serem transpostas no futuro.

Nessa mesma perspectiva, Jörn Rüsen, historiador e filósofo da história, ao elaborar sua tipologia da consciência histórica (2010b), interpretou as diferentes alternativas construídas pelos seres humanos para propiciarem sentido às suas experiências, à sua vivência histórica, à sua orientação no tempo. Propôs um sistema de desenvolvimento das operações mentais do pensamento histórico que, em síntese, visa trazer à memória as experiências; experiências que devem ser interpretadas em sua historicidade, pois constitui-se em ponto fulcral considerar as contingências a elas relacionadas (em seus diferentes momentos e lugares ao longo do processo histórico); e, finalmente, por meio das operações de rememoração e interpretação, constituir orientação ao presente, recuperando o passado e antecipando o futuro. Enfim, percebeu que o olhar reflexivo em direção ao passado é algo importante que todos podem (e devem) fazer. Avançou. Compreendeu que a ciência histórica aprendida nos bancos universitários pode (e deve) contribuir para que as pessoas, em seu cotidiano, construam consciência histórica, pois em sua visão a História, enquanto ciência, tem de ter constante e dinâmico diálogo com a vida. ${ }^{3}$

Percebe-se que o trabalho de Rüsen tem um caráter inovador por investir na racionalização de sentido relacionando ciência da História e cotidiano de vida, pois para ele a concepção de consciência histórica resultante dessa relação possibilita outra perspectiva para o trabalho do historiador ao permitir a ampliação tanto do corpus investigativo quanto do corpus epistemológico da História. Rüsen não pode ser considerado um teórico do Ensino de História, tal qual se compreende tradicionalmente no Brasil, mas um historiador e filósofo da

\footnotetext{
${ }^{3}$ Para Rüsen "[...] são quatro os tipos de consciência histórica. A consciência histórica tradicional se relaciona à permanência inquestionável de valores morais e modos de vida tradicionalmente estabelecidos, doando ao tempo um caráter estável, repetitivo. Na consciência histórica exemplar ou modelar o passado fornece princípios que podem ser usados como modelo para situações de vida no presente - aquilo que Cícero chamou na Antiguidade de "História Mestra da Vida". A consciência histórica crítica, por sua vez, se relaciona a uma postura crítica dos indivíduos a valores morais tradicionalmente estabelecidos, pois pensa cultura como algo que se transforma ao longo do tempo. Finalmente, a consciência histórica genética avança em relação a posturas de aceitação ou rejeição do passado, pois entende que mudanças e permanências estão sujeitas ao tempo e, portanto, devem ser historicizadas" (ALVES, 2015, p. 326-327).
} 
História que pensa a partir da função da denominada Didática da História ${ }^{4}$. Para ele, a ciência da História tem uma função pública e o espaço escolar, nessa perspectiva, trata-se de um importante meio (mas não o único) de criação e sistematização do conhecimento histórico na sociedade. Assim, as ideias de Rüsen e de outros autores dessa linha de investigação pertencente à História, na Alemanha5, abriram espaço, paulatinamente, para que pesquisas empíricas fossem feitas, ligadas diretamente à metodologia e prática do ensino de História, tanto na Alemanha, como em outros lugares do mundo que sofreram influência dessa abordagem epistemológica, inclusive o Brasil. Tal como afirmam Barom e Cerri (2012, p. 1002):

\begin{abstract}
Neste sentido, o conceito de consciência histórica acaba por redimensionar a Didática da História, porque pressupõe que todo ser humano conhece história e pratica algum tipo de atribuição de sentido ao tempo, sendo a ciência da história um deles, não o único modo possível ou aceitável. Assim, ensinar história não pode ser transmitir algo da ciência para o vulgo, mas um diálogo entre focos de produção de sentidos. Uma história que retorna à sociedade como forma de orientação, regulada metodicamente, e que partiu dela, das necessidades que as pessoas têm de agir no mundo, num processo constante de interpretação.
\end{abstract}

Como pode ser observado, Rüsen pensou a História como ciência intrinsecamente relacionada à vida e, por isso, mostrou ser fundamental que sua metodologia e formas de apresentação do resultado de seu trabalho tenham a finalidade de contribuir, política e esteticamente, com a formação do pensamento histórico das pessoas. Processo que possibilita aos seres humanos o encontro com a alteridade, o relacionamento dialógico com perspectivas divergentes, enfim, a reflexão constante a respeito dos modelos, tradições, ideologias, representações subjacentes à(s) cultura(s) prescrita(s) a cada ser humano desde seu nascimento, mas passíveis de serem reproduzidas, rejeitadas, criticadas, transformadas.

\footnotetext{
${ }^{4}$ A Didática da História se trata de uma linha de investigação da História, na Alemanha, que teve suas perspectivas de pesquisa, após sua reorientação nos anos 1970, "[...] grandemente expandidas, indo além de considerar apenas os problemas de ensino e aprendizado na escola. A didática da história analisa agora todas as formas e funções do raciocínio e conhecimento histórico na vida cotidiana, prática. Isso inclui o papel da história na opinião pública e as representações nos meios de comunicação de massa; ela considera as possibilidades e limites das representações históricas visuais em museus e explora diversos campos onde os historiadores equipados com essa visão podem trabalhar (RÜSEN, 2010a, p. 31-32).

${ }^{5}$ Destacam-se Klaus Bergmann, H-J Pandel, K-E Jeismann, dentre outros.
} 
Num mundo em que modelos de orientação temporal têm sido largamente propagandeados nos meios de comunicação - o Estado confundido com o Mercado; lucros privatizados em detrimento dos prejuízos, publicizados; cidadania atendendo pela capacidade de consumo individual; entre tantos outros dilemas contemporâneos - a construção de uma consciência histórica que possibilite reflexão constante a respeito da cultura histórica é fundamental.

Então... como se constitui a consciência histórica?

O conteúdo da consciência histórica de indivíduos e grupos se apresenta nas diferentes formas pelas quais opera mentalmente o raciocínio histórico. São três as operações mentais do pensamento histórico: experiência [do alemão Erfahrung], interpretação ou significado [Bedeutung] e orientação ou sentido [Sinn].

A primeira delas, denominada experiência no tempo se constitui como a atividade intelectual que possibilita a criação de propostas de concretização de suas intencionalidades de ação, na própria experiência de vida. Em conceitos koselleckianos, é a capacidade intelectual de rememorar experiências passadas articulando-as ao seu próprio espaço de experiência com as expectativas vislumbradas a serem praticadas no decurso da vida, portanto, inseridas em seu horizonte de expectativas. Para isso, o pensamento se constitui como histórico à medida que recorre à memória com o fim de recuperar como indivíduos, grupos sociais, nações e sociedades agiram em seu tempo com o objetivo de diferenciálo de sua própria ação no presente. A consciência histórica se apresenta, assim, num aspecto do pensamento histórico que permite aos seres humanos 0 enfrentamento do cotidiano por meio da relação entre suas intenções de ação e as experiências do tempo vivenciado. Essa operação mental revela certo pragmatismo, pois articula a ação à temporalidade da vida do sujeito. Mostra a capacidade de diagnosticar os problemas cotidianos, construir resoluções e vivenciá-las praticamente em seu próprio tempo por meio da comparação com a experiência passada. Rüsen (2010b) chamou isso de sensibilidade histórica, os pesquisadores da Educação Histórica ${ }^{6}$ de forma mais sistematizada, relacionam

\footnotetext{
${ }^{6}$ A Educação Histórica (History Education) trata-se de uma "[...] linha de investigação [que] tem seus fundamentos pautados em indagações como as que buscam entender que sentidos os jovens, as crianças e os professores atribuem a determinados conteúdos históricos como revolução francesa, renascimento e reforma protestante, chamados de "conceitos substantivos", e/ou os "conceitos de segunda ordem", tais como narrativa, explicação ou evidência histórica.
} 
essa operação mental a uma das características do conceito de literacia histórica, como afirma Schmidt (2009, p. 17):

[...] pode-se caracterizar a literacia histórica como a construção de sujeitos historicamente letrados, que sejam minimamente capazes de $[. .$.$] ter uma imagem do passado que Ihes permita orientarem-$ se no tempo, a qual exige o domínio de determinados conteúdos históricos ou uma compreensão substantiva coerente do passado.

Uma segunda operação mental que expressa a consciência histórica se apresenta em sua relação com a abertura do horizonte de expectativas. Trata-se daquela que confere significado à experiência. Ler e compreender o passado histórico com profundidade passa pela ação cognitiva de encontrar os interesses que originaram as ideias geradoras das experiências decorridas e interpretá-los à luz dos parâmetros existentes em determinado contexto histórico. Somente assim é possível promover o entendimento do processo histórico que levou à satisfação (ou não) das carências de orientação dos seres humanos do período histórico discutido. Significado aqui, se refere à compreensão das motivações que nutriram a experiência vivida, ou seja, trata-se de interpretar a experiência no tempo. Tal interpretação se origina da busca pelo significado da experiência no passado a partir do cotejamento com as demandas de orientação do presente. Essa dinâmica comparativa de experiências interpretadas racionalmente abre perspectivas para o futuro (RÜSEN, 2010c, p. 97). Em outras palavras, experiência e expectativa são unidas por representações de continuidade, geradas pela atividade hermenêutica do intérprete.

A utilização dessa operação mental da consciência histórica não se limita somente ao trabalho de descrever, datar ou inserir numa cronologia a experiência, antes se direciona a interpretar essa experiência temporal com empatia histórica. Esse conceito pode ser definido como uma "realização - algo que acontece quando procuramos compreender o que o agente histórico pensou, quais seus objetivos, como entenderam aquela situação e se conectamos tudo isto com o que os agentes fizeram" (LEE, 2003, p. 19). Portanto, construir

(LEE, 2001; BARCA, 2005), e as ações deles decorrentes, apreendidos e conceituados em e a partir de contextos concretos de ensino, bem como articulados aos modos de educar de cada época e sociedade." (SCHMIDT; GARCIA, 2006, p. 21). Nascida no Reino Unido, na transição das décadas de 1960/70, essa linha de investigação tem se espalhado em vários países, dentre eles Portugal e Brasil (ALVES, 2013, p. 60). 
empatia histórica trata-se de um difícil trabalho cognitivo de se transportar intelectualmente para a época estudada de forma a esforçar-se para pensar as motivações que levaram os habitantes do passado a suas ações, sem prejulgamentos morais ou éticos, utilizando-se, portanto, da historicidade necessária para a análise da produção documental de dado tempo.

Essa operação mental é fundamental para o desenvolvimento de consciência histórica, pois permite compreender o processo de arquitetura das opções e suas ações históricas sem recorrência ao erro do anacronismo, tão comum à sociedade. É, por exemplo, ter a possibilidade de criar respostas a perguntas que invariavelmente aparecem em salas de aula, como as relacionadas à escravidão na Antiguidade e Modernidade, à servidão na Medievalidade ou a ação nazifacista na Contemporaneidade, dentre outras. Perguntam: como as pessoas daquela época permitiram isso? Por que a população não evitou essas situações de opressão e horror se era maioria em comparação com os líderes de suas sociedades? O desenvolvimento da operação de interpretação da experiência no tempo, ou seja, a utilização acurada de empatia histórica pode auxiliar indivíduos, grupos sociais, nações e sociedades a evitarem ações históricas trágicas que ceifaram a vida de milhões de pessoas. Essa operação mental do conhecimento histórico revela outra característica de indivíduos e grupos que desenvolvem literacia histórica:

[...] pode-se caracterizar a literacia histórica como a construção de sujeitos historicamente letrados, que sejam minimamente capazes de $[. .$.$] ter um conhecimento de como desenvolver uma explicação$ e narrativa do passado, o que pressupõe o domínio de ideias substantivas e de ideias de segunda-ordem [meta-históricas] que colaborem para organizar o passado, fazendo com que 0 conhecimento do passado seja possível (SCHMIDT, 2009, p. 1819).

Enfim, as operações mentais do pensamento histórico - experiência no tempo e interpretação da experiência no tempo - mostram que os seres humanos se apropriam do conhecimento histórico conscientemente com o objetivo de vencer os obstáculos de sua própria vivência no tempo.

Ler, interpretar o passado, dotar-Ihe de significado. Compreender as opções históricas dos indivíduos e sociedades em seu tempo. Direcionar-se no presente a partir da reconstrução do passado e prospecção do futuro. As operações 
mentais da consciência histórica até então tratadas apresentam características endógenas, ou seja, voltadas para si mesmas à medida que dependem da ação interna do sujeito no que concerne à rememoração do passado, reflexão do presente e prospecção do futuro. No entanto, a consciência histórica não se limita apenas à reflexão interna. Ela tem de se manifestar de alguma forma. Deve se relacionar com o mundo que serviu de matéria-prima para a rememoração e reflexão no tempo. Dessa forma, faz-se necessário exprimir tal consciência, construída a partir da interpretação das experiências rememoradas (e/ou co-memoradas) e significadas, com o fim de exercer novas opções históricas orientadas por um planejamento. É na operação mental de orientação que os seres humanos têm a possibilidade de mostrarem a si mesmos em suas opções históricas de agir no mundo que os cerca. Ela é o resultado cognitivo derivado da relação existente entre o conhecimento histórico adquirido e o pensamento histórico elaborado:

[...] Essa competência pode se definir como a habilidade da consciência humana para levar a cabo procedimentos que dão sentido ao passado, fazendo efetiva uma orientação temporal na vida prática presente por meio da recordação da realidade passada (RÜSEN, 2010b, p. 59).

A operação mental de orientação da experiência interpretada do tempo se apresenta às pessoas no ato de narrar. É por meio da narrativa que o conhecimento histórico - oriundo da ciência da História, transmitido às pessoas por influência da educação escolar ou dos inúmeros meios de informação e mediados pelas operações mentais do pensamento histórico - se apresenta como produto cognitivo para orientação da vida prática. Ela é a porta-voz das operações mentais do pensamento histórico, pois é a forma de linguagem utilizada pelos seres humanos para apresentar a orientação da aplicação do pensamento histórico à vida prática - a consciência histórica. É na narrativa histórica que indivíduos, grupos sociais e nações expressam o sentido de sua consciência histórica. As ações cognitivas que implicam a leitura do passado histórico e o presente vivido (literacia), em seus significados interpretados no tempo da experiência (empatia), só podem apresentar seu sentido se forem expressos na forma linguística. Por meio da narrativa histórica os seres humanos revelam os interesses, as perspectivas e os objetivos de suas ações no tempo. 
Dessa forma, não é qualquer narrativa que pode ser considerada histórica. É preciso obedecer a alguns critérios para avaliar a narrativa como de caráter histórico:

\begin{abstract}
A narrativa não é sempre e basicamente histórica [...] 'Histórico' significa [...] que o passado é interpretado, com relação à experiência, no constructo próprio a uma 'história' e que essa interpretação passa a ter função na cultura contemporânea. Como nem toda narrativa de histórias está relacionada com a experiência do passado e serve para torná-la presente, é necessário especificar a narrativa histórica no conjunto dos elementos comuns às narrativas histórica e não histórica. É comum ambas atuarem como um modo específico de constituição de sentido sobre a experiência do tempo. Narrar a partir do tempo faz sentido na medida em que a sequência temporal dos acontecimentos (na maior parte ocorrências ou conteúdos empíricos de tipo estrutural) é situada no contexto próprio a esses mesmos acontecimentos (RÜSEN, 2001, p. 154-155).
\end{abstract}

Portanto, para ser considerada histórica uma narrativa deve conter a ação das operações mentais supracitadas relacionando as três temporalidades com o objetivo de apresentar perspectivas de orientação existencial e construir identidade, ou seja, deve apresentar as funções da consciência histórica. Sendo assim, a narrativa só se constituirá como histórica se recorrer ao meio que o conduzirá ao passado histórico: as lembranças que, trabalhadas em seu contexto histórico individual e coletivo se tornam memória histórica a ser utilizada como matéria-prima para o processo interpretativo de orientação no tempo presente. O resultado desse trabalho hermenêutico representa a sinergia entre passado e presente com vistas à seleção do que deverá ser continuado e descontinuado na prospecção do futuro. Dessa seleção surgem representações de continuidade, ou seja, concepções de temporalidade que comporão o que permanecerá no processo histórico, pois são elas que qualificarão o passado rememorado ao vinculá-lo, estruturalmente, ao presente interpretado e ao futuro prospectado. Por outro lado, o material descontinuado terá como fim o esquecimento, pois ao sujeito produtor da narrativa histórica não apeteceu dar status de permanência a essas lembranças.

A consciência histórica aparece exatamente na capacidade de seleção de lembranças que atingirão o status de rememoração e a criação de representações que as mediarão, via interpretação, sintetizando as diferentes 
temporalidades numa continuidade (RÜSEN, 2001, p. 65). Exemplos de representações de continuidade ocorrem desde as mais simples situações cotidianas familiares até as ações artísticas, políticas ou mesmo historiográficas. Objetos, lugares com carga sentimental para pais e avós são representativos para filhos e netos; filmes em época de democracia que discutem a opressão em tempos de ditadura; trabalhos historiográficos que optam em esquecer momentos históricos traumáticos para a sociedade, optando por um tempo passado áureo, são exemplos de representações de continuidade.

Como se vê, a criação de representações de continuidade unificadoras das temporalidades guarda em si a questão da autoria, pois está diretamente relacionada à identidade das pessoas, grupos sociais e nações, pois é a narrativa histórica, composta por lembranças transformadas em memória pela razão histórica e, selecionada de acordo com o que interessa ser continuado no tempo, que comporá a identidade (que se pretende) perene no futuro e sintetizará as três temporalidades, pois a

[...] constituição de sentido sobre a experiência do tempo mediante a narrativa histórica, se trata afinal de contas da identidade daqueles que têm de produzir esse sentido da narrativa (histórica), a fim de poderem orientar-se no tempo. Toda narrativa (histórica) está marcada pela intenção básica do narrador e de seu público de não se perderem nas mudanças de si mesmos e de seu mundo, mas de manterem-se seguros e firmes no fluxo do tempo. [...] A resistência dos homens à perda de si e seu esforço de autoafirmação constituem-se como identidade mediante representações de continuidade, com as quais relacionam as experiências do tempo com as intenções no tempo [...]. A narrativa histórica é um meio de constituição da identidade humana (RÜSEN, 2001, p. 66).

É da importância de orientação no tempo que trata o excerto acima. Essa operação mental revela a identidade do produtor da narrativa histórica. Nesse sentido, História como ciência e Vida como práxis cotidiana se encontram na narrativa histórica. Ela, como porta-voz da articulação entre as operações mentais do pensamento histórico, atua de maneira exógena a fim de dar a conhecer ao mundo o resultado desse trabalho cognitivo. Para ser histórica é necessário que o sentido da narrativa esteja diretamente vinculado à experiência no tempo, pois o passado rememorado deve se tornar presente como fonte interpretada à luz da cultura contemporânea e, consequentemente, gerar perspectivas de orientação temporal. Perspectivas que representarão a 
identidade de seu sujeito e aquilo que apresenta a seu público. Nesse sentido, a narrativa histórica é poiesis (WHITE, 1995), ou seja, é "feitura" no sentido de um produto autoral que constitui o conhecimento histórico, pois toma os feitos do passado como experiência a ser mediada pelo presente com o fim de gerar orientação para o futuro. Afinal, a competência de orientação

[...] supõe ser capaz de utilizar o todo temporal, com seu conteúdo de experiência, para os propósitos de orientação da vida. Implica guiar a ação por meio das noções de mudança temporal, articulando a identidade humana com o conhecimento histórico, mesclando a identidade no enredo e na própria trama concreta do conhecimento histórico (RÜSEN, 2010b, p. 60-61).

As operações mentais do pensamento histórico (experiência no tempo e interpretação da experiência no tempo) constituem consciência histórica ao se defrontarem com os desafios da práxis de vida, gerando possibilidades de orientação no tempo. Dessa forma, ter consciência histórica é utilizar-se do pensamento histórico, por meio da narrativa histórica, com o fim de dar sentido às suas experiências no tempo e à sua identidade. Nessa perspectiva, tal como constata Lee (2008, p. 11), as pessoas tornam-se letradas historicamente:

[...] Se os estudantes são capazes de fazer sentido do passado e adquirirem algum conhecimento do que podemos dizer acerca dele, e em simultâneo ser capaz de utilizar esse conhecimento de modo a que tenha claramente uma utilizadade/aplicabilidade, se tal acontecer talvez possa afirmar-se que os estudantes são historicamente letrados.

\section{III}

Depreende-se dessa digressão, a respeito da importância da construção de consciência histórica por meio de suas diferentes operações mentais com a finalidade de dotar as ações históricas de sentido, que é mister a necessidade de formar professores e pesquisadores que possam fomentar esse trabalho junto aos estudantes da escola básica para que possam perceber a importância do conhecimento histórico em sua própria orientação no dia a dia, bem como à construção de identidade.

Assim, pesquisadores de várias partes do mundo têm se colocado a pensar a respeito da construção do conhecimento histórico nas escolas, seja por meio de 
investigações com estudantes, professores, materiais didáticos, fontes históricas de diferentes tipos e tantos outros objetos de pesquisa, com o fim de analisar como ocorre a aprendizagem histórica tanto em seu conteúdo substantivo, quanto em sua constituição meta-histórica (ou seja, relacionada aos anteriormente mencionados "conceitos de segunda ordem").

Com o objetivo de melhor compreender a formação das operações mentais do pensamento histórico no âmbito escolar, categorias de análise têm sido elaboradas, firmadas nas diferentes maneiras pelas quais estudantes, professores, currículos e materiais didáticos compreendem, explicam, se apropriam de fontes, aproximam-se da produção histórica em sua historicidade. Pesquisadores utilizam tais categorias como meio de aproximarem as concepções da racionalidade científica à aprendizagem histórica escolar. Essa aproximação não se configura como uma forma de tornar os alunos pequenos historiadores, mas sim de possibilitar instrumentos que permitam compreender que o conhecimento histórico não reside simplesmente na memorização dos fatos passados, institucionalizados nos manuais didáticos, meios de comunicação ou narrativas dos professores. Por outro lado, tampouco se limita a ser um agrupamento de fatos históricos de um passado longínquo que não faz sentido algum para a vida contemporânea. Para eles, relacionar a racionalidade histórica à vida é tornar sólido um trabalho analítico que possibilite ao estudante, entre outras coisas, o conhecimento das experiências vivenciadas pelos seres humanos ao longo do tempo; a interpretação dessas práticas à luz das demandas e instrumentos hermenêuticos existentes no presente; e a geração de sentido para as experiências futuras, individuais e/ou coletivas.

Nesse sentido, a contribuição da Didática da História à formação do pensamento histórico passa pela construção de caminhos que potencializem o uso dos conceitos meta-históricos, por parte dos estudantes, para gerar conhecimento sob a perspectiva da constituição de sentido à História. Em outras palavras: é desenvolver o potencial de trazer à memória a experiência humana, significá-la por meio de um processo interpretativo e dotar de sentido a experiência futura que compõe o horizonte de expectativas. Em síntese: a produção de conhecimento histórico, no processo de formação escolar deve passar, necessariamente, pelo objetivo de construir consciência histórica racionalmente. 
Dessa forma, as operações mentais do pensamento histórico - experiência, interpretação e orientação - além de continuarem sua função como operações mentais inerentes a todos os seres humanos, tornam-se, também, dimensões que relacionam a História, enquanto ciência, à vida prática. Assim, a Didática da História, pode promover diversas possibilidades de investigação em espaços intra e extraescolares, tal como afirma Rafael Saddi:

[...] Para nós, a didática da história, como subdisciplina da Ciência Histórica que investiga a consciência histórica predominante em uma sociedade, não se reduz nem ao ensino escolar da História nem às elaborações da história sem forma científica. Ao se colocar na tarefa de estabelecimento da 'Morfologia', da 'Gênese' e da 'Função' da consciência histórica, e, em sua tarefa normativa, atuar como uma 'Pragmática' da didática da história, ela desenvolve sua investigação em três áreas fundamentais: a) o ensino escolar da história, em que atua como uma didática do ensino de história; b) o uso público da história, em que se estabelece como uma didática da história pública; e c) a ciência história, em que age como uma didática da ciência histórica ou uma instância de auto-reflexão dos historiadores (SADDI, 2012, p. 215-216).

É nessa perspectiva epistemológica oriunda da relação entre a racionalidade da ciência histórica e a aprendizagem histórica em espaços intra e extraescolares que o presente artigo apresenta o processo que deu origem ao LEPEDIH Laboratório de Estudos e Pesquisas em Didática da História na Universidade Estadual Paulista "Júlio de Mesquita Filho", Campus de Assis.

Estranhamento. Esta é a palavra que poderia definir, resumidamente, o encontro entre os 65 estudantes da $49^{a}$ turma formanda no curso de História da UNESP/Assis e a epistemologia da Didática da História, presente na disciplina Prática do Ensino de História e Estágio Supervisionado $\mathrm{II}^{7}$, no quarto e último ano da licenciatura, no ano de 2012. Disciplina na qual os estudantes, ao longo do ano letivo, deveriam elaborar um projeto de ensino com o uso de fontes históricas na sala de aula, desenvolvê-lo no estágio supervisionado numa escola de ensino básico e, finalmente, escrever um artigo científico que refletisse a respeito dessa experiência. Desafio intenso, pois logo na chegada à universidade se pode perceber o total desconhecimento acerca da pesquisa em Ensino de História, suas correntes epistemológicas construídas historicamente dentro e fora do Brasil, bem

\footnotetext{
7 Por conta da reformulação da grade curricular do curso de História da UNESP/Assis, feita no corrente ano, essa disciplina passou a se chamar "Metodologias do Ensino de História".
} 
como de sua importância para o aprimoramento da formação docente. ${ }^{8}$

Por sugestão de um grupo de estudantes da 49a turma de História da UNESP/Assis e de alguns alunos participantes do projeto de extensão chamado Projeto de Educação de Jovens e Adultos (PEJA) da UNESP/Assis ${ }^{9}$, surgiu, em junho de 2012, o Grupo de Estudos em Ensino de História com a finalidade de discutir textos relacionados à pesquisa em Ensino de História para além da formação na graduação. A ideia era constituir, em médio prazo, um grupo de pesquisa que promovesse estudos que contribuíssem para problematizar a mentalidade de desconhecimento e desconexão entre a construção do conhecimento histórico na academia e a formação histórica dos estudantes da escola básica. Em outras palavras, que discutisse a importância da relação do conhecimento histórico com a vida das pessoas, ou seja, que se pensasse na função pública da ciência histórica.

Enfim, era necessário construir um espaço de experiências novo na universidade, com a finalidade de abrir um horizonte de expectativas para a pesquisa em ensino de História e a qualificação da formação de professoreshistoriadores. Assim, uma série de frentes de trabalho relacionando as três áreas que compõem o sustentáculo da universidade - o ensino, a pesquisa e a extensão - se constituiu para, paulatinamente, promover a compreensão de que o Ensino de História apresenta uma plêiade de possibilidades de pesquisa dada sua característica de ser região de fronteira entre a História e a Educação (MONTEIRO; PENNA, 2011).

O fato de ser um espaço fronteiriço entre a História e a Educação traz várias dificuldades de identidade para a pesquisa no Ensino de História, algo claro quando se observa o recorrente debate em torno do lugar do pesquisador dessa linha de investigação nos programas de pós-graduação no Brasil (afinal, tal pesquisador

\footnotetext{
${ }^{8}$ Convém mencionar que, diferentemente de várias universidades públicas estaduais e federais no Brasil, as quais possuem uma média de 10 a 20 alunos (no máximo) supervisionados por docente, as universidades públicas estaduais paulistas (UNESP, USP e UNICAMP) apresentam grande atraso no cumprimento da legislação a respeito de estágios supervisionados. No caso da UNESP/Assis o número de estagiários por docente, atualmente, no curso de História, varia de 60 a 70 estágios/ano.

9 Mayra de Andrade Medina, Ágata Indira de Oliveira, Tamires Fiorucci, Marcela Alves, Jéssica Proença, Ariane Grimaldi Tudela van Dal e Thayla Theodoro (todas do $4^{\circ}$ ano de História em 2012), Luís Gustavo Ayres e Vinícius Rodrigues ( $2^{\circ}$ ano de História), Silmária Reis e Paulo Fernando Toledo de Oliveira ( $1^{\circ}$ ano de História), Sayne Regina Quirino Oliveira (licenciada em História e estudante do $1^{\circ}$ ano do curso de Letras) e Bianca Xavier Moreira (Licenciada em História).
} 
deve orientar/ser orientado na História ou na Educação?), entretanto a característica epistemológica da Didática da História que compreende ser a racionalidade proveniente da História base para sua pesquisa, promove a intersecção entre esses espaços fronteiriços, pois compreende que a aprendizagem histórica ocorre por diferentes meios na sociedade e deveria manter relação direta com o conhecimento histórico criado pelos especialistas, historiadores, na universidade. Em outras palavras, a Didática da História se ocupa em estudar a relação entre a formação do pensamento histórico e sua contribuição para que as pessoas construam consciência histórica, ou seja, se orientem temporalmente por meio da racionalidade histórica e se conheçam e (re)conheçam o outro, identitariamente.

Nessa perspectiva História e Educação se relacionam, pois a formação histórica gerada na universidade tem a função de satisfazer carências de orientação das pessoas na sociedade. Para isso, o conhecimento gerado em âmbito acadêmico chega à escola básica não somente por conteúdos e temáticas, mas (e, sobretudo) pelo desenvolvimento das operações mentais próprias da racionalidade que somente o estudo da História oferece, seja por meio do trabalho de investigação feito por professores e estudantes em diferentes tipos de fontes, passando pelas discussões em torno das questões de historicidade, ou mesmo do estudo da relação entre as diferentes temporalidades como fruto da investigação a respeito da produção humana no tempo, etc. Ações cognitivas que também podem ser investigadas no processo de construção do conhecimento resultante do encontro das pessoas com a História em espaços extraescolares (diferentes mídias, espaços museológicos, patrimoniais, entre outros). Assim, o pesquisador do Ensino de História na perspectiva da Didática da História o faz partindo da teoria e de recursos metodológicos provenientes da História, porém promove sua relação com recursos teóricos e, principalmente, metodológicos, oriundos de outras áreas do conhecimento, tais como a Antropologia, a Sociologia e a Psicologia Social.

Este é um importante ponto de ligação entre a proposta da teoria da
história rüseniana e a área do ensino da história. A consideração de
que ao agir no mundo o homem precisa interpretá-lo, não como um
dado puro, mas à luz de suas memórias e experiências. [...] Ou seja,
todo ser humano, em ambiente de escolarização ou não, recorre a
alguma forma de atribuição de sentido ao agir no mundo, na
intenção de satisfazer os seus interesses. Ao relocar o papel do
historiador, da torre de marfim, isolado na academia, 
autolegitimado, a uma condição de cidadão comum, imerso na sociedade, com também interesses e carências, Rüsen então realiza um engate entre a produção do historiador e a satisfação de seus interesses, de sua época, de seu público alvo. O que sugere uma ligação direta entre o conhecimento histórico produzido cientificamente e a função de orientação que ele pode exercer em seu meio de circulação (BAROM; CERRI, 2012, p. 1002).

Para iniciar e desenvolver essa perspectiva de investigação na UNESP/Assis, vários desafios têm sido enfrentados. O primeiro deles se vinculava ao fato de trabalhar com os estudantes da graduação somente no ano final do curso. Era necessário criar espaços de aproximação dessa perspectiva com estudantes de anos iniciais do curso a fim de diminuir, paulatinamente, o estranhamento com a perspectiva da Didática da História. Algo que começou a ocorrer por meio do trabalho desenvolvido em projetos de extensão e de ensino na universidade, atraindo estudantes dos anos iniciais da graduação do curso de História e, até mesmo, de outros cursos (caso de estudantes de Letras e Psicologia) para o grupo de estudos em Ensino de História. Nessa perspectiva, o primeiro projeto desenvolvido, desde o início de trabalho na UNESP, como demanda do Departamento de Educação, foi o PEJA - Projeto de Educação de Jovens e Adultos.

O PEJA é um dos programas institucionais da UNESP que existe em sete campi diferentes, tendo sido criado por esta universidade, no final do ano 2000, com o fim de contribuir para a erradicação do analfabetismo no país e, concomitantemente, possibilitar a seus licenciandos a oportunidade de aprender, praticamente, o ofício da docência, bem como a realização de pesquisas em EJA. No campus de Assis, o PEJA atua em seis salas localizadas nos municípios de Assis e Cândido Mota, com aproximadamente 20 graduandos bolsistas e voluntários dos cursos de História, Letras e Psicologia ${ }^{10}$, que lecionam para 50 a 70 alunos divididos nos espaços citados. Trata-se de um projeto de alfabetização e letramento que tem a concepção freireana (FREIRE, 2008; 2011a; 2011b; 2014; BRANDÃO, 2008) de educação popular como principal referencial teóricometodológico, além do estudo de trabalhos relacionados à perspectiva do letramento (SOARES, 2008; SOARES; PRAZERES; COSTA, 1998). Como não há

\footnotetext{
10 No ano de 2014 o projeto teve a participação de um estudante do curso de Engenharia Biotecnológica entre seus educadores. Entretanto, desde 2012 não há participação de estudantes do curso de Biologia, provavelmente por tratar-se de um curso de período integral, fator que dificulta a permanência na atual estrutura do projeto, com salas que atendem a comunidade, sobretudo, nos períodos da tarde e da noite.
} 
curso de Pedagogia na UNESP/Assis, tampouco especialistas no processo de alfabetização e letramento no projeto, ambos, coordenação e educadores licenciandos, desenvolvem estudos semanais de formação e projetos que procuram utilizar diferentes tipos de fontes históricas para construção do conhecimento. O trabalho junto aos educandos ocorre com a discussão de diversos temas, diretamente relacionados ao cotidiano dos participantes ou mesmo a questões estruturais da sociedade, tais como meio ambiente, cidadania, democracia, violência, racismo, desigualdade social, discussões de gênero, direitos dos idosos e das crianças, entre outros, por meio de textos literários em prosa e poesia (clássicos, cordéis, em haicai, da denominada "literatura marginal", etc.), passando por imagens (propagandas televisivas, folders de estabelecimentos comerciais, propagandas de revistas, jornais, histórias em quadrinhos, mapas, etc.), músicas (de diferentes gêneros e épocas), cultura material (objetos pessoais, discussão a partir de espaços museológicos, monumentos, etc.), entre outros, de forma que os educandos alfabetizados possam encontrar-se com discussões contemporâneas e, assim, aprimorarem-se na leitura, escrita e construção textual, bem como os educandos, no início do processo de alfabetização, possam encontrar-se com as letras por meio de palavras geradoras suscitadas de rodas de conversa estimuladas por círculos de cultura - espaços fundamentais para a construção do conhecimento coletivo entre educadores e educandos (BRANDÃO, 1996). Faltava ao projeto o desenvolvimento de pesquisas que pudessem estudar a importância do PEJA-UNESP/Assis, tanto na formação de professores quanto (e, principalmente) na vida das pessoas simples que formam seu público-alvo.

Nesse sentido, nos anos de 2014/15 desenvolveu-se a primeira pesquisa de iniciação científica no PEJA-UNESP/Assis com uma bolsista Fundação de Amparo à Pesquisa do Estado de São Paulo (FAPESP), licenciada em História, graduanda em Psicologia e educadora do PEJA-UNESP/Assis. A pesquisa intitulada "Memória e Representações Sociais no Projeto de Educação de Jovens e Adultos (PEJA) da UNESP-Campus de Assis/SP" teve como objetivo analisar as representações dos alunos participantes do PEJA no que diz respeito a falta de acesso à educação e os desdobramentos disso em sua vida cotidiana, por meio da metodologia da História Oral (MEIHY, 2002), de forma que pudesse ser traçado um histórico com o fim de compreender o processo de (re)inserção desses sujeitos na sociedade letrada. Parte da pesquisa foi publicada na Revista História e Diversidade e, atualmente, 
novo artigo está em processo de escrita com o resultado final do trabalho (SANTOS; ALVES, 2014). Percebe-se que, embora o PEJA-UNESP/Assis seja um projeto de extensão que tem como objetivo a alfabetização e o letramento de seus educandos, tem se revelado, paralelamente, num espaço importante para a formação de professores de diferentes áreas do conhecimento, além de fomentador de pesquisas. Devido à atual característica de formação acadêmica da coordenação, o PEJA-UNESP/Assis procura relacionar extensão e pesquisa ao ensino tendo, como pano de fundo, epistemologia que procura, em última análise, fomentar a construção da consciência histórica e política, por meio do trabalho com fontes históricas em sala de aula. ${ }^{11}$

Outro importante projeto desenvolvido na perspectiva da formação de professores na UNESP/Assis é o Programa Institucional de Bolsa de Iniciação à Docência (PIBID). Fomentado pela CAPES/MEC, o programa tem como objetivo promover o aperfeiçoamento e a valorização da formação de professores para a educação básica e concede bolsas a estudantes de cursos de licenciatura de instituições de ensino superior que atuam em parceria com escolas de educação básica da rede pública de ensino.

No caso do subprojeto História da UNESP/Assis (Edital 2014-2017) são 24 bolsistas que atuam em quatro escolas do município de Assis, sob a supervisão de quatro professores (um em cada escola) e a coordenação na universidade de dois docentes. ${ }^{12}$ O PIBID História UNESP/Assis trabalha com a formação continuada dos bolsistas licenciandos e dos professores das escolas acolhedoras no intuito de desenvolver atividades didático-pedagógicas que possibilitem a construção do conhecimento histórico, por meio da interpretação de diferentes tipos de fontes históricas (escritas, imagéticas, orais, materiais, sonoras, audiovisuais, etc.) estudadas transversalmente às temáticas abordadas em sala de aula. Para exemplificar essa prática, pode-se pensar num estudo com o tema de fundo "Segunda Guerra Mundial" desenvolvido pelos pibidianos, por meio da investigação de fontes imagéticas relacionadas à propaganda dos diferentes grupos políticos que participaram do conflito. Por outro lado, pode-se pensar,

\footnotetext{
${ }^{11}$ A respeito de possibilidades de diálogo entre a teoria da consciência histórica, na perspectiva de Jörn Rüsen e os diferentes conceitos criados por Paulo Freire, referentes à consciência política e o processo de conscientização, cf. SCHMIDT; GARCIA (2005); SCHMIDT (2011) e DIVARDIM (2012).

12 Os coordenadores do PIBID-História da UNESP/Assis são os professores Alonso Bezerra de
} 
também, em projetos de prazo maior que utilizam-se de um tipo de fonte histórica a ser trabalhada em vários temas como, por exemplo, a literatura nas aulas de História, cinema e ensino de História, etc. Após amadurecer a formação relacionada à elaboração de ações didáticas que visam o intercâmbio de conhecimento entre professores experientes e jovens professores, O PIBIDUNESP/Assis, pretende avançar, neste segundo momento do projeto, na construção de pesquisas em Ensino de História em diferentes vertentes.

Outro projeto de formação de professores desenvolvido na UNESP-Assis chama-se "O uso das linguagens no Ensino de História como meio de aprendizagem: um desafio ao professor-pesquisador" e pertence ao Núcleo de Ensino da UNESP (Editais 2013/2014). Projeto que teve como objetivo contribuir para futuros professores, e docentes em exercício, elaborarem propostas de trabalho que utilizem diferentes linguagens como fonte histórica para a aprendizagem dos estudantes, bem como oferecer elementos teóricometodológicos que possibilitem a interpretação das representações de seus alunos. Ao longo dos dois anos de trabalho, três bolsistas e uma professora participaram do projeto vinculado a uma escola estadual pública localizada no município de Assis. Tal projeto suscitou trabalhos específicos com cinema, música e histórias em quadrinhos, enquanto fontes históricas para construção do conhecimento, junto aos estudantes das turmas que acolheram o projeto. Um artigo foi publicado em decorrência deste projeto (ALVES, 2014) e outros dois estão em processo de revisão para publicação no Programa Núcleo de Ensino da UNESP, pertencente à Pró-Reitoria de Graduação (PROGRAD).

Projetos em escolas, como os acima apresentados, fomentam pesquisas de diferentes matizes no ensino de História, como as voltadas para a análise de práticas de professores e estudantes, a utilização de fontes históricas como meio para formação do pensamento histórico, a análise da aplicação de políticas públicas referentes ao ensino de História no espaço escolar, a análise de conteúdo do material didático e de sua apropriação na escola por estudantes e professores, dentre outras.

Além dos projetos acima citados se encontra em pleno andamento, outro projeto de extensão denominado "Laboratório de Estudos e Pesquisas em Didática da História (LEPEDIH): organização do acervo de materiais didáticos", o qual tem

Carvalho e Ronaldo Cardoso Alves, ambos do Departamento de Educação. 
como objetivo higienizar, organizar e constituir um acervo de livros didáticos de História, doados pelo Ministério da Educação (MEC) ao Centro de Documentação e Apoio à Pesquisa da UNESP/Assis (CEDAP) ${ }^{13}$, aprovados no Programa Nacional do Livro Didático (PNLD) 2004 e Programa Nacional do Livro Didático e Programa Nacional do Livro Didático para o Ensino Médio (PNLEM) 2008 com a finalidade de disponibilizá-lo aos pesquisadores, sobretudo em Ensino de História, para a investigação das políticas públicas de avaliação e distribuição de materiais didáticos, bem como do conteúdo dos manuais didáticos em si, desenvolvendo, dentre várias possibilidades, estudos acerca de como as diferentes coleções trabalham a diversidade tipológica documental; ou em que medida cumprem a legislação e editais; quais as concepções de História e de Ensino de História existentes/predominantes nas obras; as opções historiográficas e as formas com as quais tais narrativas são trabalhadas; os processos de avaliação, etc.

Encontra-se em processo de finalização um catálogo que permitirá ao pesquisador que tenha acesso, por exemplo, à incidência dos diferentes tipos de fonte histórica nas diversas coleções, os textos historiográficos mais utilizados pelas obras, entre outras tantas possibilidades. Além disso, está em processo final de desenvolvimento um website de mesmo nome (http://www.lepedih.org) que visa ser um espaço informativo importante para pesquisadores e professores com acesso a links de revistas e dossiês e laboratórios de Ensino de História de várias universidades do país, links de bibliotecas digitais, museus virtuais, arquivos com diferentes tipos de documentos históricos, etc. Neste projeto há a atuação de uma bolsista vinculada à PROEX - Pró-Reitoria de Extensão Universitária da UNESP e três voluntários no CEDAP.

Por fim, essas frentes de trabalho, com projetos que promovem a intersecção entre ensino, extensão e pesquisa, fortaleceram o Grupo de Estudos em Ensino de História, criado no ano de 2012, e deram origem a um Grupo de Pesquisas registrado no $\mathrm{CNPq}$, denominado "Laboratório de Estudos e Pesquisas em Didática da História (LEPEDIH)", o qual reúne pesquisadores de três universidades distintas (UNESP, USP e UFRRJ) ${ }^{14}$ e possui graduandos que atuam ou atuaram nos projetos

\footnotetext{
${ }^{13}$ A doação deste material ao CEDAP, autorizada pelo MEC, foi viabilizada pela professora Tânia Regina de Luca, do Departamento de História da FCL - UNESP/Assis, participante da equipe de coordenação da área de História, dos processos avaliativos do PNLD e PNLEM mencionados.

${ }^{14}$ Katia Maria Abud (USP), Regina Maria de Oliveira Ribeiro (UFRRJ) e Lúcia Helena Oliveira Silva e Ronaldo Cardoso Alves (UNESP/Assis).
} 
mencionados acima. Trata-se de um grupo novo que pretende atuar em três linhas de pesquisa: "Políticas públicas, formação de professores, currículos e materiais didáticos"; "Fontes Históricas no aprendizado histórico"; e "História do Ensino de História, Narrativas, Memórias e Representações".

O LEPEDIH da UNESP/Assis teve como fonte de inspiração espaços laboratoriais de diferentes universidades que têm trabalhado na perspectiva da aprendizagem histórica. As experiências desenvolvidas por diferentes pesquisadores acerca dos estudos da consciência histórica no Centro de Pesquisa em Didática da História (CEPEDIH), coordenado pela professora Kátia Maria Abud, na Faculdade de Educação da Universidade de São Paulo (USP), bem como o processo de discussões teóricas, feitas por este grupo, em torno de autores da Didática da História, serviram como base para a criação do laboratório da UNESP/Assis ${ }^{15}$. Além do CEPEDIH, outros dois laboratórios serviram de inspiração para o LEPEDIH. Um deles é o Laboratório de Pesquisa em Educação Histórica (LAPEDUH), criado e coordenado pela professora Maria Auxiliadora Schmidt, na Universidade Federal do Paraná (UFPR), que tem atuado em várias frentes na perspectiva investigativa da Educação Histórica ao promover importante intercâmbio com pesquisadores da Universidade do Minho, em Portugal, orientados pela professora Isabel Barca, além de publicar revistas, traduzir e publicar livros com textos de Jörn Rüsen, e desenvolver uma série de projetos de formação junto aos professores do ensino básico de escolas do estado do Paraná. O outro espaço laboratorial que inspirou a criação do LEPEDIH-UNESP/Assis foi o Laboratório de Ensino de História da Universidade Estadual de Londrina (UELPR), criado pela professora Marlene Rosa Cainelli e outros pesquisadores. Laboratório que tem suscitado diferentes pesquisas relacionadas à aprendizagem histórica, orientadas pelas professoras Marlene Cainelli e Márcia Elisa Teté

\footnotetext{
15 No CEPEDIH iniciei a trajetória como pesquisador em Ensino de História desenvolvendo dois trabalhos sob a orientação da Katia Maria Abud - a dissertação de mestrado intitulada "Representações Sociais e a Construção da Consciência Histórica" (2006) e a tese de doutorado "Aprender História com Sentido para a Vida: consciência histórica em estudantes brasileiros e portugueses"(2011), tendo o prazer de compartilhar das experiências de pesquisa em ensino de História com vários pesquisadores, igualmente vinculados ao CEPEDIH e orientados por Katia Maria Abud, com trabalhos de mestrado e/ou doutorado já defendidos na Faculdade de Educação da USP: André Chaves de Melo e Silva (2005; 2010), Milton Joeri Fernandes Duarte (2005; 2011), Regina Maria de Oliveira Ribeiro (2006; 2012), Ricardo Barros (2007); Murilo José de Resende (2008; 2013), Thelma Cadermatori Figueiredo de Oliveira (2008); José Norberto Soares (2009) e Daniel Carlos Knoll (2014). Todos esses trabalhos estão disponíveis no banco de teses e dissertações da Universidade de São Paulo (http://www.teses.usp.br/).
} 
Ramos. A Revista História \& Ensino, que publica o presente dossiê no qual se encontra este artigo, é fruto do trabalho deste laboratório. ${ }^{16}$ Além desses grupos de pesquisa, existem vários outros investigadores espalhados em diferentes regiões do país que desenvolvem pesquisas tendo como inspiração o repertório epistemológico oriundo da Didática da História alemã e da History Education (Educação Histórica) britânica. ${ }^{17}$

Em síntese, pesquisas em Ensino de História na perspectiva teóricometodológica aqui apresentada, que partem de um repertório epistemológico da História para pesquisar o Ensino de História com o objetivo de discutir a construção do conhecimento histórico e sua contribuição para orientação temporal e constituição identitária, volta-se para múltiplos objetos, tal como afirma outro teórico da Didática da História alemã, Klaus Bergmann:

[...] as formas e os conteúdos da socialização histórico-política dos diversos grupos, camadas e classes sociais e as qualidades e efeitos das consciências históricas resultantes dessa socialização. Incluem-se como objetos, também, todos os veículos e meios de comunicação que contribuem na formação de consciência histórica, como, p. ex.: televisão, rádio, vídeo, imprensa, conversas cotidianas, museus, literatura histórica, propaganda histórica, representações científicas e históricas do passado, livros didáticos, livros para jovens que tratam de assuntos históricos, monumentos históricos, edifícios e nomes de ruas que lembram eventos históricos [...] e o ensino de História [...]. Está ligada a esta atividade a investigação empírica da aula de História, que pretende perceber empiricamente a relação entre sua intenção e seus resultados (BERGMANN, 1989/90, p. 32).

Diante desse percurso que apresentou aspectos teóricos e um breve histórico da constituição de um novo espaço de formação de professores de História e de pesquisadores do Ensino de História na UNESP/Assis, aberto está o caminho para que sejam realizadas pesquisas referentes à função pública da aprendizagem histórica, bem como acerca da construção e desenvolvimento da consciência histórica na sociedade. São várias as possibilidades de pesquisa em

\footnotetext{
16 Menciona-se, também, o GEDHI (Grupo de Estudos em Didática da História), laboratório constituído pelo Prof. Luís Fernando Cerri, na Universidade Estadual de Ponta Grossa - UEPG/PR que desenvolve pesquisas qualitativas e quantitativas tendo como referencial epistemológico basilar teóricos da Didática da História alemã.

17 Na transição do século XX para o XXI ocorre importante intercâmbio entre a Didática da História alemã e a History Education britânica, pois os estudos teóricos de Jörn Rüsen acabam por auxiliar pesquisadores britânicos preocupados com a aprendizagem histórica na escola básica, conforme pode ser observado em ALVES, 2013.
} 
Ensino de História que poderão ser desenvolvidas no LEPEDIH, tais como as investigações em torno de políticas públicas referenciadas no Ensino de História em diferentes perspectivas (formação de professores, currículos, materiais didáticos, dentre outros); trabalhos que discutam a história do Ensino de História, as narrativas, memórias e representações de professores, estudantes e instituições escolares, etc; pesquisas que verifiquem como professores, estudantes, materiais didáticos, dentre outros, se apropriam dos diferentes tipos de fontes históricas (escritas, imagéticas, sonoras, audiovisuais, orais e da cultura material, etc.) para construção do conhecimento histórico; estudos que discutam em que medida meios ou espaços extraescolares de exposição de informações de cunho histórico (diferentes mídias, museus, etc.) fundamentam-se em critérios do conhecimento histórico cientificamente produzido; pesquisas que pensem a relação entre a construção do conhecimento histórico na educação superior e na educação básica, bem como o papel da Ciência da História para o Ensino de História escolar; dentre tantas outras possibilidades.

Como pôde ser observado ao longo do texto, o LEPEDIH se trata de um simples espaço laboratorial de pesquisas em Ensino de História, organizado, paulatinamente, numa instituição importante na formação de professores de História no estado de São Paulo, gerada entre experiências e expectativas. Experiências. Porque se inspira em espaços laboratoriais de universidades importantes nos estudos da formação da consciência histórica, as quais comungam da preocupação com a formação de professores de História que compreendam ser a racionalidade histórica fundamental, não somente para sua constituição enquanto historiadores e docentes, mas para a formação do pensamento histórico dos estudantes da escola básica. Estudantes que não se formarão historiadores no ensino fundamental e médio, mas perceberão a importância do estudo da História para conscientização de si mesmos como agentes históricos numa sociedade carente de plena cidadania, premente de ampliação da democracia em diferentes matizes, e demandante de melhoria da saúde das relações humanas para que minorias e excluídos possam ter lugar para suas vozes, historicamente asfixiadas. Expectativas.

Destarte, o espaço fronteiriço que permite intersecções entre a História e a Educação, confere uma série de dificuldades para aqueles que ousam pesquisar o ensino de História na perspectiva de promover a relação entre o conhecimento histórico e a vida das pessoas, instituições, grupos, enfim, da sociedade no 
tempo.

Tal como a experiente poetisa desafia seus leitores em suas palavras geradoras de expectativas, a formação de professores de História e de pesquisadores em ensino de História não pode se deixar levar pelas vicissitudes do tempo, pelas dificuldades que visam ceifar o desejo de busca pelo conhecimento histórico. Num momento de claro recrudescimento e ampliação de ideias conservadoras no mundo e, em especial, na sociedade brasileira em que avanços dos direitos humanos de grupos historicamente excluídos têm sido questionados e, até mesmo, legalmente tolhidos, é premente a construção de uma mentalidade que promova em professores historiadores o desejo da "remoção de pedras" de uma mentalidade vigente nos cursos de licenciatura em História no Brasil, a qual marginaliza a construção do conhecimento histórico por parte dos professores e estudantes da escola básica; que incentive a constante (re)criação do conhecimento histórico ou mesmo a perene construção de experiências de forma que o estudo da História possa ser fonte para todos "os sedentos". Dura coisa é "tomar a parte que cabe" a cada professor de História, a cada pesquisador do Ensino de História nesse processo, a partir do próprio lugar, por menor que seja, de forma que "novas páginas possam ser escritas", experiências possam ser geradas, a fim de que não sejam travadas, asfixiadas, páginas que possam ser partilhadas "aos que tem sede" de aprender e viver, enfim... expectativas. As gerações de grandes pesquisadores do Ensino de História que iniciaram esse caminho de investigação no Brasil enfrentando desafios imensos, partilharam de suas experiências. Legado que deve referenciar as novas gerações de pesquisadores dessa linha de investigação, inspirando-a, alimentando-a, de maneira que prossigam, criando experiências e expectativas. Assim, baseando-se nas sábias palavras da poetisa, o estudo da História poderá "viver no coração dos jovens e na memória das gerações que hão de vir."

\section{Referências}

ALVES, R. C. A aula de História como lugar do ensino, da pesquisa e da extensão. Revista Espaço Pedagógico. Passo Fundo, v. 21, p. 274-287, 2014. . História e Vida: o encontro epistemológico entre Didática da História e 
Educação Histórica. História \& Ensin., Londrina, v. 19, p. 49-69, 2013.

Por um Ensino de História com Sentido para a Vida. Revista Diálogos.

Maringá, v. 19, p. 323-343, 2015.

BARCA. I. Fundamentos da pesquisa em educação histórica. Seminário realizado no Programa de Pós-Educação em Educação-UFPR. Programa Professor VisitanteCNPq. Curitiba, set./out. 2005.

BAROM, W. C. C.; CERRI, L. F. A Teoria da História de Jörn Rüsen entre a Modernidade e a Pós-modernidade: uma contribuição à Didática da História.

Revista Educação \& Realidade, Porto Alegre, v. 37, n. 3, p. 991-1008, set./dez. 2012.

BERGMANN, K. A História na Reflexão Didática. Revista Brasileira de História, São Paulo, v. 9, n. 19, p. 29-42, set. 1989/fev. 1990.

BRANDÃO, C. R. O que é método Paulo Freire? Coleção Primeiros Passos, 38. São Paulo: Brasiliense, 2008.

DIVARDIM, T. A relação ensino e aprendizagem histórica como práxis: a Educação Histórica e a formação de professores. 2012. 214f. Dissertação (Mestrado em Educação) - Faculdade de Educação, Universidade Federal do Paraná, 2012.

FREIRE, P. Conscientização: teoria e prática da libertação: uma introdução ao pensamento de Paulo Freire. 3 ed. São Paulo: Centauro, 2008.

. Educação como prática da liberdade. 14 ed. Rio de Janeiro: Paz \& Terra, $2011 a$.

Pedagogia da esperança: um reencontro com a pedagogia do oprimido. 17 ed. São Paulo: Paz \& Terra, 2011b.

Pedagogia do oprimido. 58 ed. Rio de Janeiro: Paz \& Terra, 2014.

KOSELLECK, R. Futuro Passado: contribuição à semântica dos tempos históricos. Rio de Janeiro: Contraponto; Editora da PUC-Rio, 2006.

LEE, P. Progressão da compreensão dos alunos em História. BARCA, Isabel (Org.). Perspectivas em Educação Histórica: Actas das I Jornadas Internacionais de Educação Histórica. Braga: Centro de Investigação em Educação - Instituto de Educação e Psicologia - Universidade do Minho, 2001, p. 13-27.

- Nós fabricamos carros e eles tinham que andar a pé: compreensão da vida no passado. In: BARCA, Isabel (Org.). Educação Histórica e Museus: Actas da II Jornadas Internacionais de Educação Histórica. Braga: Centro de Investigação em Educação - Instituto de Educação e Psicologia - Universidade do Minho, 2003, p. 19-36.

. Educação Histórica, consciência histórica e literacia histórica. In: BARCA, Isabel (Org.). Estudos de Consciência Histórica na Europa, América, Ásia e 
África: Actas das VII Jornadas Internacionais de Educação Histórica. Braga: Centro de Investigação em Educação - Instituto de Educação e Psicologia Universidade do Minho, 2008, p. 11-32.

MEIHY, J. C. S. B. Manual de História Oral. 5 ed. São Paulo. Edições Loyola, 2005.

MONTEIRO, A. M. F. da C.; PENNA, F. de A. Ensino de História: saberes em lugar de fronteira. Revista Educação \& Realidade. Porto Alegre, v. 36, n. 1, p. 191-211, jan./abr., 2011.

Didática da História: passado, presente e perspectivas a partir do caso alemão. In: SCHMIDT, M. A.; BARCA, I.; MARTINS, E. de R. (Org.). Jörn Rüsen e o ensino de História. Curitiba: Editora UFPR, p. 23-40, 2010 a.

. O desenvolvimento da competência narrativa na aprendizagem histórica: uma hipótese ontogenética relativa à consciência moral. In: SCHMIDT, M. A.; BARCA, I.; MARTINS, E. de R. (Org.). Jörn Rüsen e o ensino de História. Curitiba: Editora UFPR, p. 51-77, 2010b.

. Narrativa Histórica: fundamentos, tipos, razão. In: SCHMIDT, M. Auxiliadora; BARCA, I.; MARTINS, E. de R. (Org.). Jörn Rüsen e o ensino de História. Curitiba: Editora UFPR, 2010c, p. 93-108.

Razão histórica: teoria da história: fundamentos da ciência histórica. Brasília: Editora Universidade de Brasília, 2001.

SADDI, R. O parafuso da didática da história: o objeto de pesquisa e o campo de investigação de uma didática da história ampliada. Acta Scientiarum Education. Maringá, v. 34, n. 2, p. 211-220, jul.-dez., 2012.

SANTOS, S. R.; ALVES, R. C. História Oral, Memória e Representações Sociais: diálogos com a educação de pessoas adultas. História e Diversidade/ Revista do Departamento de História. Cáceres, v. 4, n. 1, p.179-187, 2014.

SCHMIDT, M. A. A Cultura como referência para investigação sobre consciência histórica: diálogos entre Paulo Freire e Jörn Rüsen. In: BARCA, I. (Org.). Atas das XI Jornadas Internacionais de Educação Histórica. Realizadas de 15 a 18 de Julho de 2011, Instituto de Educação da Universidade do Minho/Museu D. Diogo de Sousa, Braga.

- Literacia Histórica: um desafio para a Educação Histórica do século XXI. História \& Ensino, Londrina, v. 15, p. 9-22, ago. 2009.

SCHMIDT, M. A.; GARCIA, T. M. B. A Formação da consciência histórica de alunos e professores e o cotidiano em aulas de História. Caderno Cedes, Campinas, v. 25 , n. 67, p. 297-308, set./dez. 2005.

Pesquisas em Educação Histórica: algumas experiências. Educar. Curitiba, Especial, p. 11-31, 2006. 
SOARES, M. Alfabetização e letramento. São Paulo: Contexto, 2008. . Letramento: um tema em três gêneros. 4 ed. Belo Horizonte: Autêntica, 2010.

WHITE, H. Meta-História: a imaginação histórica do século XIX. 2 ed. São Paulo: EDUSP, 2008.

Recebido em 19 de novembro de 2014 Aprovado em 18 de dezembro de 2015 